\title{
RESEARCH
}

Open Access

\section{Opioid agonist therapy uptake among people who inject drugs: the findings of two consecutive bio-behavioral surveillance surveys in Iran}

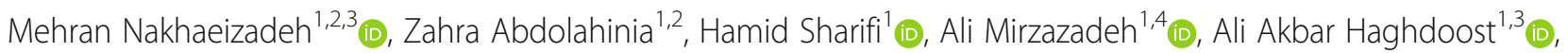
Mostafa Shokoohi ${ }^{1,5,6}$ (D) Stefan Baral ${ }^{7}$ (D) Mohammad Karamouzian ${ }^{1,8}$ (D) and Armita Shahesmaeili ${ }^{1^{*}}$ (D)

\begin{abstract}
Background: Opioid agonist therapy (OAT) uptake has been associated with multiple positive health outcomes among people who inject drugs (PWID). This study evaluated the pattern of OAT uptake among PWID in two consecutive national bio-behavioral surveillance surveys (2010 and 2014) in Iran.

Methods: Data were obtained from two national bio-behavioral surveillance surveys ( $N_{2010}=1783$ and $N_{2014}=$ 2166) implemented using convenience sampling at the harm reduction facilities and street venues in 10 geographically diverse urban centers across Iran. Multivariable logistic regression models were built to determine the correlates of OAT uptake for the 2014 survey, and adjusted odds ratios (AORs) along with 95\% confidence intervals $(\mathrm{Cl})$ were reported.

Results: The prevalence of OAT uptake decreased from $49.2 \%$ in 2010 to $45.8 \%$ in 2014 ( $P$ value $=0.033$ ). OAT uptake varied across the studied cities ranging from 0.0 to $69.3 \%$ in the 2010 survey and 3.2 to $75.5 \%$ in the 2014 survey. Ever being married ( $A O R=1.40 ; 95 \% \mathrm{Cl} 1.12,1.75)$, having a history of incarceration ( $\mathrm{AOR}=1.56 ; 95 \% \mathrm{Cl}$ 1.16, 2.09), and human immunodeficiency virus (HIV) sero-positivity ( $A O R=1.63 ; 95 \% \mathrm{Cl} 1.08,2.50$ ) were associated with OAT uptake. Conversely, PWID who reported using only non-opioid drugs (AOR $=0.43 ; 95 \% \mathrm{Cl} 0.26,0.71$ ) and those who reported concurrent use of opioid and non-opioid drugs ( $\mathrm{OOR}=0.66 ; 95 \% \mathrm{Cl} 0.51,0.86$ ) were less likely to uptake OAT.

Conclusions: Although OAT uptake among PWID in Iran is above the $40 \%$ threshold defined by the World Health Organization, there remain significant disparities across urban settings in Iran. Importantly, the OAT services appear to be serving high-risk PWID including those living with HIV and those with a history of incarceration. Evaluating service integration including mental health, HIV and hepatitis $C$ virus care, and other harm reduction services may support the optimization of health outcomes associated with OAT across Iran.
\end{abstract}

Keywords: Opioid agonist therapy, People who inject drugs, Harm reduction, Surveillance, Iran

\footnotetext{
*Correspondence: a.shahesmaeili@kmu.ac.ir; armita.shahesmaeili@gmail.com 'HIV/STI Surveillance Research Center, and WHO Collaborating Center for HIV Surveillance, Institute for Futures Studies in Health, Kerman University of Medical Sciences, Kerman, Iran, Haftbagh Highway, Kerman 7616913555, Iran Full list of author information is available at the end of the article
}

(c) The Author(s). 2020 Open Access This article is licensed under a Creative Commons Attribution 4.0 International License, which permits use, sharing, adaptation, distribution and reproduction in any medium or format, as long as you give appropriate credit to the original author(s) and the source, provide a link to the Creative Commons licence, and indicate if changes were made. The images or other third party material in this article are included in the article's Creative Commons licence, unless indicated otherwise in a credit line to the material. If material is not included in the article's Creative Commons licence and your intended use is not permitted by statutory regulation or exceeds the permitted use, you will need to obtain permission directly from the copyright holder. To view a copy of this licence, visit http://creativecommons.org/licenses/by/4.0/. The Creative Commons Public Domain Dedication waiver (http://creativecommons.org/publicdomain/zero/1.0/) applies to the data made available in this article, unless otherwise stated in a credit line to the data. 


\section{Introduction}

One of the most populated countries in the Middle East and North Africa (MENA) region is Iran where over one million people are estimated to use illicit drugs [1]. Moreover, the number of people who inject drugs (PWID) is estimated to be 280 per 100,000 population, about half of whom are infected with hepatitis $\mathrm{C}$ virus (HCV) and around $13.8 \%$ are living with human immunodeficiency virus (HIV) [2-4]. To reduce HIV, $\mathrm{HCV}$, and other blood borne infections among PWID, a comprehensive and innovative harm reduction (HR) program has been implemented in Iran. Currently, healthcare facilities including voluntary counseling and testing (VCT) centers, HR centers for vulnerable women, shelters, prisons, antenatal clinics, and drop-in centers (DICs) provide onsite or outreach HR services to PWID. These services include but are not limited to opioid agonist therapy (OAT) by methadone, buprenorphine, or opium tincture, as well as needle and syringe programs (NSPs), VCT, and free condom distribution $[5,6]$.

Although buprenorphine maintenance therapy (BMT) and opium tincture are available in Iran, methadone maintenance treatment (MMT) programs are more common [1]. MMT programs were initially implemented in pilot projects in 2002; however, they were significantly scaled up in public and private clinical settings from 2003-2007. By September 2014, MMT was offered to PWID at 5744 private centers and 239 public centers supervised by State Welfare Organization, medical sciences universities, or prisons' organization [7]. As of 2018, over 700,000 participants have received MMT programs in these centers [6]. The cost of MMT services is considerably lower in public centers [8].

OAT in PWID has been associated with several beneficial public health outcomes including decreasing the rate of fatal and non-fatal overdose, reducing the rate of HIV and $\mathrm{HCV}$ transmission, lowering the rate of violence, diminishing social costs associated with drug use, increasing PWID's quality of life, and improving their employment status [9-13]. For PWID who are less connected to healthcare services, OAT could also represent a gateway to other services such as primary health care, HIV testing and counseling, antiretroviral therapy, and tuberculosis, $\mathrm{HCV}$, and sexually transmitted infections (STI) care [14]. Our understanding of the prevalence and patterns of OAT uptake among PWID in Iran is limited. To monitor the impact of OAT programs in prevention of $\mathrm{HIV}, \mathrm{HCV}$, and hepatitis $\mathrm{B}$ virus (HBV), it is crucial to know the current level of OAT uptake among PWID in Iran. In response, we aimed to identify the prevalence and trend of OAT among PWID and determine the factors associated with OAT uptake using the data collected in two national consecutive bio-behavioral surveillance surveys conducted in urban settings across Iran in 2010 and 2014.

\section{Methods}

\section{Study design and participant}

Data from the $2010(N=1783)$ and 2014 $(N=2166)$

HIV national bio-behavioral surveillance surveys (BBSS) were used to assess the prevalence of OAT uptake among PWID in Iran. As PWID bear the highest burden of HIV on Iran, nation-wide surveys are conducted every few years to help monitor the trend of HIV and its related risk behaviors among this population and inform the national HIV response. The 2010 and 2014 surveys were conducted in 10 geographically diverse cities. Study participants were recruited from shelters, DICs, VCT centers, and street-based venues through outreach efforts. Eligible participants were 18 years or more and self-reported injection drug user for at least once during the previous 12 months. The details of the surveys are previously described $[4,15]$.

\section{Data collection}

Data were collected through face-to-face interviews using a structured questionnaire consisted of sociodemographic characteristics, illicit drug use practices, sexual behaviors, knowledge about STI and HIV, history of incarceration, history of HIV testing, drug use treatment, and care-seeking behaviors. Individuals were given a monetary incentive equivalent to 5 USD for their participation.

\section{Dependent variable: OAT uptake}

The outcome variable in the present study was OAT uptake. Participants were asked "Have you received any type of prescribed OAT including MMT, buprenorphine maintenance treatment, or treatment with opium tincture within the last month?" Responses were recorded as yes (coded as 1 ) or no (coded as 0$)$.

\section{Covariates}

These covariates included age at interview ( $\leq 35$ or $>35$ years), gender (male or female), marital status (never married or ever married), monthly income levels $(<200$ USD or $\geq 200$ USD), education levels (high school and above or less than high school), history of incarceration (yes or no), source of recruitment in the study (outreach or facility-based), substance type used in the past month (only opioid, only non-opioids, or opioids and nonopioids), self-perceived risk of HIV (yes or no), and HIV status (negative or positive). Opioids included opium, opium sap, heroin, crack, norchizak (i.e., a combination of several opioids with corticosteroids or benzodiazepines), tamchizak (i.e., a combination of industrial morphine hydrochloride and other synthetic drugs), and non-prescribed use of methadone, buprenorphine, and opium tincture. Non-opioids included hashish/grass/ 
cannabis, marijuana, ecstasy, cocaine, and methamphetamine/crystal/shisheh.

\section{Ethics}

The study protocol was reviewed and approved by the Research Review Board of the Kerman University of Medical Sciences (Ethics code No: IR.KMU.REC.597 and K/93/208), and Iran's Ministry of Health.

\section{Statistical analysis}

We first reported the prevalence of OAT uptake among PWID in two rounds. OAT uptake was also reported by subgroups of the covariates. Moreover, OAT uptake prevalence in two rounds was compared using twosample proportion tests. Participants with missing responses to OAT uptake were excluded from the relevant estimates. Bivariable and multivariable logistic regression models for the survey were constructed to assess the correlates of OAT uptake among PWID based on 2014 data. Variables with a $P$ value $<0.2$ from the bivariable models were entered into the multivariable model. The final model was selected using a backward selection approach. As participants were recruited from different cities, each one was considered as a cluster and their clustering effects were adjusted using Stata's survey package. The survey weights were calculated by dividing the total population by the sample size of each city. Crude and adjusted odds ratios (AORs) along with 95\% confidence intervals (CI) were reported. Stata version 14.1 (College Station, Texas) was used for the analyses of these data. $P$ values less than 0.05 were considered statistically significant.

\section{Results}

\section{Participants' characteristics}

In both surveys, most participants were male $(96.0 \%$ in 2010 and $98.7 \%$ in 2014), had an education less than high school (69.3\% in 2010 and $67.0 \%$ in 2014), had a history of incarceration $(81.2 \%$ in 2010 and $79.8 \%$ in 2014), and had low income levels $(76.9 \%$ in 2010 and $39.9 \%$ in 2014). Among 1783 PWID in the 2010 survey, 790 (49.2\%; 95\% CI 46.3, 52.0) and, among 2166 PWID in the 2014 survey, 905 (45.8\%; 95\% CI 43.3, 48.4) reported past month OAT uptake. Overall, the prevalence of past month OAT uptake showed a significant decreasing trend $(49.2 \%$ in 2010 vs. $45.8 \%$ in $2010, P=$ 0.033). The trend was decreasing among those with a history of incarceration (53.2\% vs. $47.7 \%$ ), those with no history of incarceration (48.2\% vs. $38.8 \%$ ), those who had ever been married ( $47.9 \%$ vs. $40.4 \%$ ), and those who had low levels of self-perceived risk of HIV (56.1\% vs. 44.3\%). The past-month OAT uptake increased over time among PWID who only used non-opioid drugs in the previous month (2.0\% vs. $32.9 \%)$ (Table 1$)$.

\section{Past-month OAT uptake in subgroups}

In both surveys, the prevalence of past-month OAT uptake was higher among people who had ever been married $(50.2 \%$ in 2010 vs. $50.3 \%$ in 2014), were older than 35 years (52.9\% in 2010 vs. $48.6 \%$ in 2014), were living with HIV (59.6\% in 2010 vs. $58.3 \%$ in 2014 ), and had a history of incarceration $(53.2 \%$ in 2010 vs. $47.7 \%$ in 2014). Conversely, the prevalence of OAT uptake was lower among those who reported last-month non-opioid drug use (2\% in 2010 vs. $32.9 \%$ in 2014) (Table 1). Moreover, OAT prevalence varied across the studied cities, ranging from $0 \%$ in Zahedan to $69.4 \%$ in Kerman in 2010 survey and 3.2\% in Ahvaz to $75.5 \%$ in Sari in 2014 survey (Fig. 1).

\section{OAT-associated factors}

In the multivariable model, being ever married $(\mathrm{AOR}=$ 1.40; 95\% CI 1.12, 1.75), HIV sero-positivity (AOR = 1.63; $95 \%$ CI 1.08, 2.50), and incarceration history (AOR = 1.56; $95 \%$ CI 1.16, 2.09) increased the odds of receiving OAT while last-month non-opioid drug use $(\mathrm{AOR}=0.43$; $95 \%$ CI $0.26,0.71)$ and last-month concurrent opioid and nonopioid drugs use $(\mathrm{AOR}=0.66 ; 95 \%$ CI 0.51, 0.86) decreased the odds of receiving OAT (Table 2).

\section{Discussion}

Our findings showed that as of 2014, less than half of PWID in Iran received OAT in the previous year with significant heterogeneity in OAT uptake across cities. Being ever married, HIV positive, and having a history of incarceration were positively associated with receiving OAT, while using non-opioid drugs were negatively associated with receiving OAT.

Moreover, we demonstrated that less than half of the surveyed PWID used OAT in the previous year. Based on the World Health Organization's (WHO) definition of high coverage of OAT (i.e., $40 \%$ or more), Iran falls into the high coverage category [16]. However, there is a high level of disparity for OAT uptake across cities with OAT uptake ranging from $0-75 \%$ in different cities. Interestingly, all cities with low OAT coverage were among the less and under developed regions, settings that also have higher rates of child mortality and lower numbers of rehabilitation centers and paramedics in comparison with the rest of the country [17]. Therefore, to reach and maintain the high coverage goal in all regions of the country, allocation of resources regarding the degree of inequality in the distribution of OAT services should be considered in future planning and financing of these services. In addition, addressing and removing the potential barriers to access and use of OAT such as financial barriers, lack of awareness and negative attitudes, worries about methadone's side effects, and social stigma attached to receiving OAT are 
Table 1 Characteristics and prevalence of past-month opioid agonist therapy (OAT) uptake among people who inject drug in Iran in two consecutive bio-behavioral surveillance surveys in 2010 ( $N=1783)$ and $2014(N=2166)$

\begin{tabular}{|c|c|c|c|c|c|c|c|c|}
\hline \multirow{2}{*}{ Variables } & & \multicolumn{3}{|l|}{2010} & \multicolumn{3}{|l|}{2014} & \multirow{2}{*}{$\begin{array}{l}P \\
\text { value }\end{array}$} \\
\hline & & $\bar{N}(\%)$ & $\begin{array}{l}\text { People with } \\
\text { OAT uptake } \\
\boldsymbol{N}(\%)\end{array}$ & $\begin{array}{l}\text { Past-month OAT } \\
\text { uptake in } 2010 \%\end{array}$ & $\bar{N}(\%)$ & $\begin{array}{l}\text { People with } \\
\text { OAT uptake } \\
\boldsymbol{N}(\%)\end{array}$ & $\begin{array}{l}\text { Past-month OAT } \\
\text { uptake in } 2014 \%\end{array}$ & \\
\hline Overall & & 1783 & $790(100.0)$ & 49.2 & 2166 & 905 (100.0) & 45.8 & 0.033 \\
\hline \multirow[t]{2}{*}{ Sex } & Male & $1732(96.0)$ & 759 (94.9) & 48.6 & 2120 (98.7) & 881 (98.2) & 45.6 & 0.063 \\
\hline & Female & $51(4.0)$ & $31(5.1)$ & 63.2 & $46(1.3)$ & $24(1.8)$ & 64.4 & 0.902 \\
\hline \multirow[t]{2}{*}{ Age at interview } & $\leq 35$ & 1054 (57.3) & $439(54.1)$ & 46.6 & 1075 (47.8) & 403 (44.6) & 42.8 & 0.077 \\
\hline & $>35$ & $725(42.7)$ & $351(45.9)$ & 52.9 & $1089(52.2)$ & $501(55.4)$ & 48.6 & 0.072 \\
\hline \multirow[t]{2}{*}{ Marital status } & $\begin{array}{l}\text { Single (never } \\
\text { married) }\end{array}$ & $816(44.9)$ & 355 (43.8) & 47.9 & $1000(44.4)$ & $380(39.1)$ & 40.4 & 0.001 \\
\hline & Ever Married & $967(55.1)$ & $455(56.2)$ & 50.2 & 1105 (55.6) & $501(60.9)$ & 50.3 & 0.963 \\
\hline \multirow[t]{2}{*}{ Income } & $\begin{array}{l}\leq 200 \text { USD }(6 \\
\text { 000,000 Rials) }\end{array}$ & 1396 (76.9) & $630(78.0)$ & 49.9 & 834 (39.9) & $332(40.0)$ & 45.9 & 0.067 \\
\hline & $\begin{array}{l}>200 \text { USD (6, } \\
\text { 000,000 Rials) }\end{array}$ & $331(23.1)$ & $138(22.0)$ & 47.0 & $1171(60.1)$ & $500(60.0)$ & 44.8 & 0.477 \\
\hline \multirow[t]{2}{*}{ Education level } & $\begin{array}{l}\text { High school } \\
\text { and above }\end{array}$ & $544(30.7)$ & $244(29.0)$ & 46.4 & $696(33.0)$ & $283(31.7)$ & 44.0 & 0.399 \\
\hline & $\begin{array}{l}\text { Less than high } \\
\text { school }\end{array}$ & 1237 (69.3) & 545 (71.0) & 50.4 & 1469 (67.0) & $621(68.3)$ & 46.7 & 0.055 \\
\hline \multirow{2}{*}{$\begin{array}{l}\text { History of } \\
\text { incarceration (ever) }\end{array}$} & Yes & $1418(81.2)$ & 624 (79.6) & 53.2 & 1651 (79.8) & 716 (82.9) & 47.7 & 0.002 \\
\hline & No & 359 (18.8) & $164(20.4)$ & 48.2 & $513(20.2)$ & 189 (17.1) & 38.8 & 0.005 \\
\hline \multirow{3}{*}{$\begin{array}{l}\text { Substance use type in } \\
\text { the past month*** }\end{array}$} & Only opioids & $1218(77.1)$ & $584(87.9)$ & 51.5 & $384(25.8)$ & $174(29.3)$ & 46.7 & 0.100 \\
\hline & $\begin{array}{l}\text { Only non- } \\
\text { opioids }\end{array}$ & $126(8.0)$ & $3(0.4)$ & 2.0 & $119(10.8)$ & $32(8.6)$ & 32.9 & $\begin{array}{l}< \\
0.001\end{array}$ \\
\hline & $\begin{array}{l}\text { Opioids and } \\
\text { non-opioids }\end{array}$ & $213(14.9)$ & $69(11.7)$ & 35.6 & $967(63.4)$ & $352(62.1)$ & 40.3 & 0.203 \\
\hline \multirow{2}{*}{$\begin{array}{l}\text { Self-perceived risk of } \\
\text { HIV }\end{array}$} & Yes & $960(58.9)$ & 393 (53.6) & 45.2 & $954(49.1)$ & $431(50.9)$ & 47.5 & 0.286 \\
\hline & No & $649(41.1)$ & $328(46.4)$ & 56.1 & $1204(50.9)$ & $469(49.1)$ & 44.3 & $\begin{array}{l}< \\
0.001\end{array}$ \\
\hline \multirow[t]{2}{*}{ HIV status } & Negative & $1408(85.0)$ & $566(81.1)$ & 44.5 & $1911(92.3)$ & $768(90.0)$ & 44.9 & 0.818 \\
\hline & Positive & $227(15.0)$ & $129(18.9)$ & 59.6 & $171(7.7)$ & $98(10.0)$ & 58.3 & 0.795 \\
\hline \multirow[t]{2}{*}{ Source of recruitment } & Outreach & $142(8.0)$ & $43(5.5)$ & 38.8 & $363(16.8)$ & $184(13.4)$ & 48.2 & 0.056 \\
\hline & Facility-based & $1641(92.0)$ & 747 (94.5) & 50.0 & $1801(83.2)$ & $720(86.6)$ & 45.4 & 0.007 \\
\hline
\end{tabular}

* $P$ values are for comparison of prevalence between two rounds of surveys in 2010 and 2014

**Type of substance: non-opioids = Shishe, hashish/grass/cannabis, marijuana, ecstasy, cocaine, and methamphetamine/crystal; opioids = opium, opium sap, opium syrup, heroin, norchizak, tamchizak, buprenorphine, methadone, and crack

integral to increasing the coverage rate of OAT uptake among Iranian PWID [8]. Tackling barriers to OAT access are of particular importance in the context of COVID-19 and future pandemics as accessing such services among PWID is often accentuated during health emergencies. Comparing our results to other countries of the MENA region, the OAT uptake in Iran seems to be higher than most of its neighboring countries. Indeed, the overall OAT provision in MENA is very limited. For example, In 2017, only 7 MENA countries provided OAT which suggests 6\% of PWID in the MENA region to be on OAT [18]. However, due to non-random nature of our study sample, these comparisons should be interpreted with caution.

The OAT uptake in PWID slightly decreased in 2014 in comparison with 2010. This trend is in opposite direction with the increasing number of facilities (from 700 centers in 2007 to 3373 centers in 2014) [19] that provide OAT services to PWID. Although the observed pattern may be simply due to possible biases in selection of the participants, it might also be due to the recent shift in substance use practices among PWID in Iran and the increase in poly-drug use involving non-opioids among them. Recent studies have shown that methamphetamine use has been 


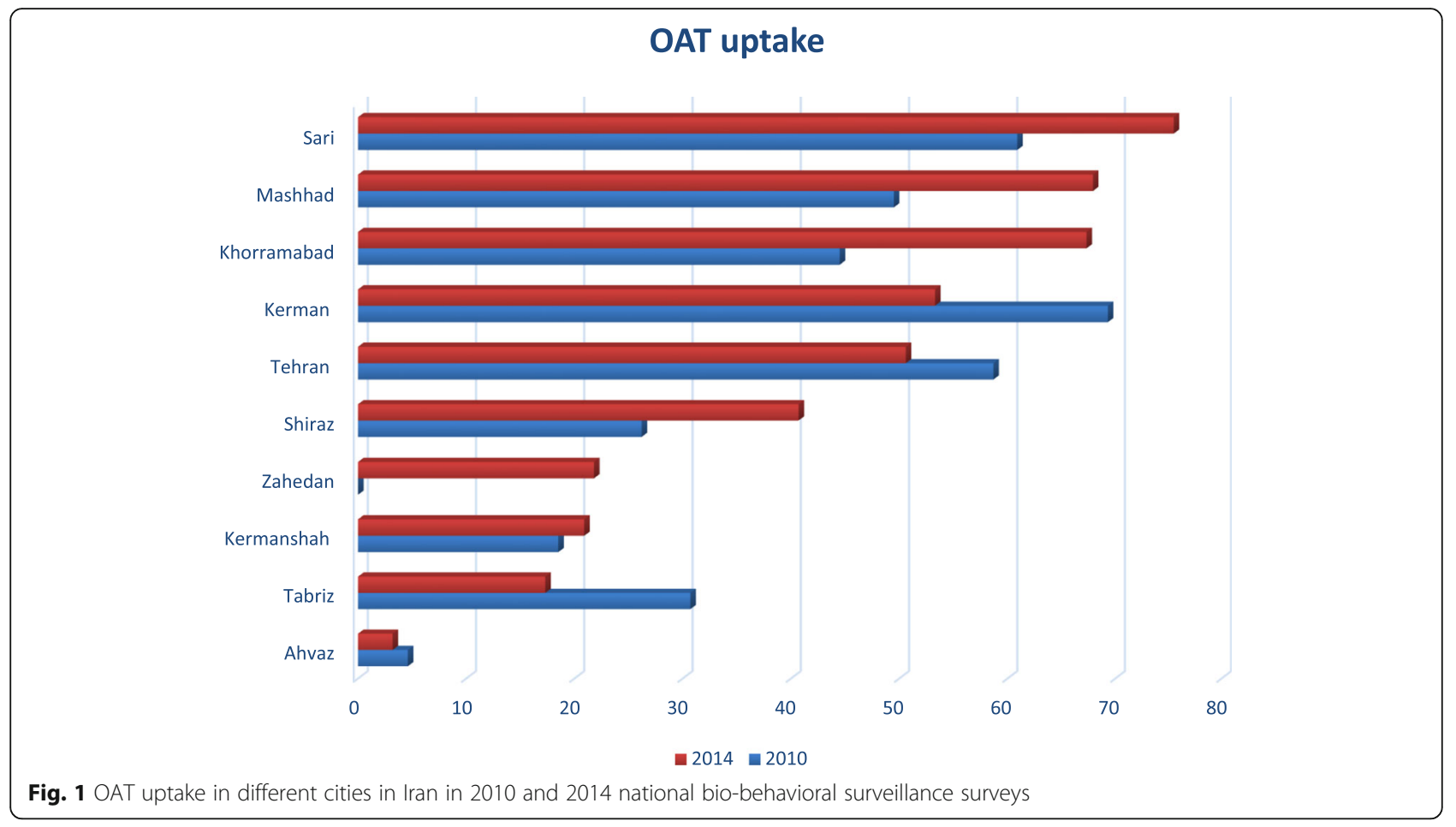

Table 2 Correlates of currently receiving opioid agonist therapy (OAT) among people who inject drug in Iran in 2014

\begin{tabular}{|c|c|c|c|c|c|}
\hline Variables & & Crude OR (95\% Cl) & $\boldsymbol{P}$ value & Adjusted OR (95\% Cl) & $\boldsymbol{P}$ value \\
\hline \multirow[t]{2}{*}{ Sex } & Male & 1 & & & \\
\hline & Female & $2.17(1.07,4.37)$ & 0.031 & & \\
\hline \multirow[t]{2}{*}{ Age at interview } & $>35$ & $1.26(1.02,1.55)$ & 0.026 & & \\
\hline & $\leq 35$ & 1 & & & \\
\hline \multirow[t]{2}{*}{ Marital status } & Single (never married) & 1 & & 1 & \\
\hline & Ever married & $1.35(1.13,1.61)$ & 0.001 & $1.40(1.12,1.75)$ & 0.004 \\
\hline \multirow[t]{2}{*}{ Income } & $\leq 200$ USD $(6,000,000$ Rials $)$ & 1 & & & \\
\hline & >200 USD (6,000,000 Rials) & $0.93(0.75,1.17)$ & 0.569 & & \\
\hline \multirow[t]{2}{*}{ Education level } & High school and above & 1 & & & \\
\hline & Less than high school & $1.11(0.89,1.38)$ & 0.336 & & \\
\hline \multirow[t]{2}{*}{ History of incarceration (ever) } & Yes & $1.43(1.12,1.84)$ & 0.005 & $1.56(1.16,2.09)$ & 0.003 \\
\hline & No & 1 & & 1 & \\
\hline \multirow[t]{3}{*}{ Substance use type in the past month ${ }^{* *}$} & Only opioids & 1 & & 1 & \\
\hline & Only non-opioids & $0.55(0.33,0.92)$ & 0.025 & $0.43(0.26,0.71)$ & 0.001 \\
\hline & Opioids and non-opioids & $0.76(0.57,0.92)$ & 0.072 & $0.66(0.51,0.86)$ & 0.001 \\
\hline \multirow[t]{2}{*}{ Self-perceived risk of HIV } & Yes & $1.13(0.92,1.40)$ & 0.223 & & \\
\hline & No & 1 & & & \\
\hline \multirow[t]{2}{*}{ HIV status } & Negative & 1 & & 1 & \\
\hline & Positive & $1.72(1.15,2.56)$ & 0.009 & $1.63(1.08,2.50)$ & 0.022 \\
\hline \multirow[t]{2}{*}{ Source of recruitment } & Outreach & 1 & & & \\
\hline & Facility-based & $0.89(0.67,1.19)$ & 0.458 & & \\
\hline
\end{tabular}

**Type of substance: non-opioids = Shishe, hashish/grass/cannabis, marijuana, ecstasy, cocaine, and methamphetamine/crystal; opioids = opium, opium sap, opium syrup, heroin, norchizak, tamchizak, buprenorphine, methadone, and crack 
increasing among PWID with opioid use disorder [20]. We also found that compared to PWID who used only opioids within the previous month, those who used only non-opioids and those who used opioids and non-opioids simultaneously, were less likely to have received OAT. Therefore, one possible explanation for the decreasing trend of OAT could be PWID's increasing tendency toward poly-drug use including stimulants.

Following the emergence and increasing supply of synthetic non-opioid drugs including methamphetamines, more PWID tend to use these drugs [21]. On the other hand, the use of methamphetamine in PWID reduces the effectiveness of OAT programs and subsequently leads to lower satisfaction of patients with OAT [22]. These issues are problematic in a way that treatment of PWID who use synthetic drugs has turned into a challenging issue within the last few years [20, 21]. In Iran, there are only a limited number of centers providing treatments for stimulant use disorder. Preliminary studies indicate that the integration of stimulant HR services into opioid HR programs at DICs could be an effective strategy in reducing high-risk behaviors of their clients [23]. Therefore, policies toward the establishment of such centers and providing treatments for stimulant use disorder at DICs should be considered in future policy and planning across the country.

Living with HIV was associated with an increased likelihood of OAT uptake, a finding which is consistent with a study conducted in Vancouver, Canada [24]. This may be partly due to the effect of post-test counseling which is freely available for all PWID who undergo HIV testing in Iran. Integration of HIV and substance use services have been shown to improve HIV treatment and care continuum among PWID living with HIV [25, 26].

In our study, having a history of incarceration was positively associated with OAT uptake. This may be due to the establishment of HR programs inside Iran's prisons. Similar to several international settings, people who use drugs are overrepresented in prisons across Iran [27, 28]. More than $50 \%$ of all Iranian prisoners are being held on drug-related offenses and $70 \%$ of them use illicit drugs [29]. When Iran experienced large outbreaks of HIV among incarcerated populations in the early 2000s, HR programs inside prisons were rapidly expanded. As these HR provision and coverage continue to function inside prisons, most PWID with a history of incarceration are likely to have used these services and received OAT during their incarceration period. Previous studies have shown that exposure of prisoners to OAT inside prisons increases their chance of receiving OAT even after their release $[18,30]$. Therefore, ensuring the continuation and extension of current strategies of HR inside prisons in Iran is of utmost importance.
We acknowledge the limitations of our study. First, social desirability bias may have resulted in over-reporting of OAT uptake and under-reporting of stigmatized and criminalized behaviors such as use of drugs and alcohol. Second, the study was cross-sectional with limited capacity for causal inference. Third, male PWID were overrepresented in our study sample and our findings may not be generalizable to female PWID in Iran. Fourth, due to non-random selection of the study participants and the possible role of selection bias, the findings might not necessarily represent OAT uptake among all PWID in Iran. Fifth, our data was collected in late 2014 and was delayed in getting published due to several contextual and logistical complexities; therefore, it might not provide a realistic picture of the current status of OAT uptake among PWID in Iran. Lastly, differences in sampling strategy between two study rounds including recruiting participants from different facilities and sites cannot be ruled out as unmeasured confounders, and therefore, comparison between the two rounds should be made with caution.

\section{Conclusion}

Despite the high level of OAT uptake among PWID, the level of heterogeneity in access to OAT in Iran is alarming. These data highlight the need to strengthen HR policies focused on providing equal access to OAT among all PWID. Furthermore, the OAT services appear to be serving PWID with a higher risk profile (e.g., those living with HIV and those with a history of incarceration). Therefore, service integration including mental health, HIV and HCV care, and other HR services may support optimal implementation and health-related impacts of OAT across Iran.

\section{Abbreviations}

OAT: Opioid agonist therapy; PWID: People who inject drugs; HIV: Human immunodeficiency virus; HCV: Hepatitis C virus; VCT: Voluntary counseling and testing; BMT: Buprenorphine maintenance therapy; MENA: Middle East and North Africa; MMT: Methadone maintenance treatment; STI: Sexually transmitted infections; HBV: Hepatitis B virus; NSPs: Needle and syringe programs; HR: Harm reduction; BBSS: Bio-behavioral surveillance surveys; WHO: World Health Organization; DICs: Drop-in centers

\section{Acknowledgements}

We would like to acknowledge the contributions of supervisors and field staff from all collaborative universities who provided inputs to the study design and methods and assisted in implementation of the surveys and data collection. We would also like to thank the participants for taking their time and sharing their valuable information. MK is supported by the Vanier Canada Graduate Scholarship and the Pierre Elliott Trudeau Foundation Doctoral Scholarship. The HIV/STI Surveillance Research Center and WHO Collaborating Center for HIV Surveillance located at Kerman University of Medical Sciences in collaboration with the Iran's Ministry of Health and Medical Education carried out the surveys.

\section{Authors' contributions}

$\mathrm{AH}$ and $\mathrm{HSH}$ conceptualized the study. AM, ASH, MK, MSH, and HSH designed the methodology and study instruments. MN performed the data processing and analysis. MN, ZA, and ASH drafted the manuscript. SB reviewed the 
manuscript and made scientific comments. All authors reviewed and edited the final manuscript and approved the submitted version.

\section{Funding}

The authors received no funding for this specific paper. The surveys were funded by the Global Fund to Fight AIDS, Tuberculosis and Malaria through UNDP Iran and by Ministry of Iran. For this paper, we also received support from the University of California, San Francisco's International Traineeships in AIDS Prevention Studies (ITAPS), US NIMH, R25MH064712.

\section{Availability of data and materials}

The datasets used and/or analyzed during the current study are available from the corresponding author on reasonable request.

\section{Ethics approval and consent to participate}

The study protocol was approved by the Research Ethics Committee (REB) at Kerman University of Medical Sciences (Ethics code No: IR.KMU.REC.597 and K/93/208). Verbal informed consent was obtained from all participants.

\section{Consent for publication}

All authors agree with the content of this manuscript and have given consent for publication.

\section{Competing interests}

All authors declare that they have no conflict of interest.

\section{Author details}

${ }^{1}$ HIV/STI Surveillance Research Center, and WHO Collaborating Center for HIV Surveillance, Institute for Futures Studies in Health, Kerman University of Medical Sciences, Kerman, Iran, Haftbagh Highway, Kerman 7616913555, Iran. ${ }^{2}$ Department of Biostatistics and Epidemiology, School of Public Health, Kerman University of Medical Sciences, Kerman 7616913555, Iran. ${ }^{3}$ Modeling in Health Research Center, Institute for Futures Studies in Health, Kerman University of Medical Sciences, Kerman 7616913555, Iran. ${ }^{4}$ Department of Epidemiology and Biostatistics, University of California San Francisco, San Francisco, CA, USA. ${ }^{5}$ Department of Epidemiology \& Biostatistics, Schulich School of Medicine \& Dentistry, The University of Western Ontario, London, Canada. ${ }^{6}$ Division of Social and Behavioural Health Sciences, Dalla Lana School of Public Health, University of Toronto, Toronto, Canada. ${ }^{7}$ Department of Epidemiology, Johns Hopkins Bloomberg School of Public Health, Baltimore, MD, USA. ${ }^{8}$ School of Population and Public Health, Faculty of Medicine, University of British Columbia, Vancouver, BC, Canada.

\section{Received: 20 April 2020 Accepted: 26 June 2020}

Published online: 22 July 2020

\section{References}

1. Nikfarjam A, Shokoohi M, Shahesmaeili A, Haghdoost AA, Baneshi MR, HajiMaghsoudi S, et al. National population size estimation of illicit drug users through the network scale-up method in 2013 in Iran. Int J Drug Policy [Internet]. Elsevier. 2016;31:147-52 https://doi.org/10.1016/j.drugpo.2016.01. 013.

2. Malekinejad M, Navadeh S, Lotfizadeh A, Rahimi-Movaghar A, Amin-Esmaeili $M$, Noroozi A. High hepatitis $C$ virus prevalence among drug users in Iran: systematic review and meta-analysis of epidemiological evidence (20012012). Int J Infect Dis [Internet]. Elsevier. 2015;40:116-30 https://doi.org/10. 1016/j.jijid.2015.09.022.

3. Rahimi-Movaghar A, Amin-Esmaeili M, Haghdoost AA, Sadeghirad B, Mohraz M. HIV prevalence amongst injecting drug users in Iran: a systematic review of studies conducted during the decade 1998-2007. Int J Drug Policy [Internet]. Elsevier. 2012;23:271-8 https://doi.org/10.1016/j.drugpo.2011.09. 002.

4. Khajehkazemi R, Osooli M, Sajadi L, Karamouzian M, Sedaghat A, Fahimfar N, et al. HIV prevalence and risk behaviours among people who inject drugs in Iran: the 2010 National Surveillance Survey. Sex Transm Infect. BMJ Publishing Group Ltd; 2013;89:iii29-iii32. doi:10.1136/sextrans-2013-051204.

5. Shahesmaeili A, Mirzazadeh A, McFarland W, Sharifi $H$, Haghdoost AA, Soori $H$. Syringe sharing in drug injecting dyads: a cross-classified multilevel analysis of social networks. AIDS Behav. Springer. 2018;22:10-8. https://doi. org/10.1007/s10461-018-2144-z.
6. Ekhtiari H, Noroozi A, Farhoudian A, Radfar SR, Hajebi A, Sefatian S, et al. The evolution of addiction treatment and harm reduction programs in Iran: a chaotic response or a synergistic diversity? Addiction. Wiley Online Library. 2019. https://doi.org/10.1111/add.14905

7. Farhoudi B, Kamali K, Gouya MM, Sedaghat A. Haghdoost A. Islamic Republic of Iran Progress Report On Monitoring of the United Nations General. 2012:1-84.

8. Khazaee-Pool M, Moeeni M, Ponnet K, Fallahi A, Jahangiri L, Pashaei T. Perceived barriers to methadone maintenance treatment among Iranian opioid users. Int J Equity Health. International Journal for Equity in Health; 2018;17:1-10. doi:https://doi.org/10.1186/s12939-018-0787-z.

9. Jarlais DCD, Des Jarlais DC. Systematic review research on needle/syringe programs and opiate substitution programs in low-and middle-income countries. J food drug Anal [Internet]. Elsevier. 2013;21:S59-61 Available from: https://doi.org/10.1016/j.jfda.2013.09.035

10. Malekinejad M, Vazirian M. Transition to injection amongst opioid users in Iran: implications for harm reduction. Int J Drug Policy. Elsevier. 2012;23: 333-7. https://doi.org/10.1016/j.drugpo.2011.09.001.

11. Razzaghi EM, Movaghar AR, Green TC, Khoshnood K. Profiles of risk: a qualitative study of injecting drug users in Tehran, Iran. Harm Reduct J. Springer; 2006:3:12. doi:https://doi.org/10.1186/1477-7517-3-12.

12. Vickerman $P$, Page $K$, Maher $L$, Hickman M. Opiate substitution treatment and HCV prevention: building an evidence base? Addiction. NIH Public Access; 2014;109:2060. doi: https://doi.org/10.1111/add.12750.

13. Pourkhajoei S, Barouni M, Noroozi A, Hajebi A, Amini S, Karamouzian M, et al. Cost-effectiveness of methadone maintenance treatment centers in prevention of human immunodeficiency virus infection. Addict Heal. Kerman University of Medical Sciences; 2017:9:81.

14. Kermode M, Crofts N, Kumar MS, Dorabjee J. Opioid substitution therapy in resource-poor settings [Internet]: SciELO Public Health; 2011. Available from: https://www.ncbi.nlm.nih.gov/pmc/articles/PMC5742414/.

15. Esmaeili A, Shokoohi M, Danesh A, Sharifi H, Karamouzian M, Haghdoost A, et al. Dual unsafe injection and sexual behaviors for HIV infection among people who inject drugs in Iran. AIDS Behav. Springer. 2019;23:1594-603. https://doi.org/10.1007/s10461-018-2345-5.

16. World Health Organization (WHO) - UNODOC - UNAIDS. WHO, UNODC, UNAIDS Technical guide for countries to set targets for universal access to HIV prevention, treatment and care for IDI. 2012; Available from: https:// apps.who.int/iris/bitstream/handle/10665/77969/9789241504379_eng.pdf; jsessionid = E6AEB02E6241765FC44B9E02F7E8B7D9? sequence $=1$.

17. Sepehrdoust $H$. Health care analysis and regional disparities in different provinces of Iran. Iran Econ Rev. University of Tehran, Faculty of Economics; 2009:14:113-34

18. Roshanfekr P, Farnia M, Dejman M. The effectiveness of harm reduction programs in seven prisons of Iran. Iran J Public Health [Internet]. Tehran University of Medical Sciences; 2013;42:1430. Available from: https://www. ncbi.n/m.nih.gov/pmc/articles/PMC4441940/.

19. Alam-mehrjerdi Z, Abdollahi M, Higgs P, Dolan K. Drug use treatment and harm reduction programs in Iran: a unique model of health in the most populated Persian Gulf country. Asian J Psychiatr. Elsevier. 2015;16:78-83. https://doi.org/10.1016/j.ajp.2015.06.002.

20. Danesh A, Noroozi A. Concurrent amphetamine and methamphetamine use among clients of opioid maintenance treatment programs in Golestan, Iran. Iran J Psychiatry Behav Sci. Kowsar; 2019;13:e74234. doi: https:/doi.org/10.5812/ijpbs.74234.

21. Radfar SR, Cousins SJ, Shariatirad S, Noroozi A, Rawson RA. Methamphetamine use among patients undergoing methadone maintenance treatment in Iran; a threat for harm reduction and treatment strategies: A qualitative study. Int J High Risk Behav Addict. Kowsar; 2016;5. doi: https://doi.org/10.5812/ijhrba.30327.

22. Zamani S, Farnia M, Tavakoli S, Gholizadeh M, Nazari M, Seddighi A-A, et al. A qualitative inquiry into methadone maintenance treatment for opioiddependent prisoners in Tehran. Iran. Int J Drug Policy. Elsevier. 2010;21:16772. https://doi.org/10.5812/ijhrba.30327.

23. Radfar SR, Mohsenifar S, Noroozi A. Integration of methamphetamine harm reduction into opioid harm reduction services in Iran: preliminary results of a pilot study. Iran J Psychiatry Behav Sci. Kowsar; 2017;11:e7730. doi:https:// doi.org/10.5812/ijpbs.7730.

24. Callon C, Wood E, Marsh D, Li K, Montaner J, Kerr T. Barriers and facilitators to methadone maintenance therapy use among illicit opiate injection drug users in Vancouver. J Opioid Manag [Internet]. 2006;2:35-41 Available from: https://www.researchgate.net/profile/David_Marsh3/publication/6487367_ 
Barriers_and_facilitators_to_methadone_maintenance_therapy_use_ among_illicit_opiate_injection_drug_users_in_Vancouver/links/56786 f9008aebcdda0ebd8bf/Barriers-and-facilitators-to-methado.

25. Haldane V, Cervero-Liceras F, Chuah FLH, Ong SE, Murphy G, Sigfrid L, et al. Integrating HIV and substance use services: a systematic review. J Int AIDS Soc. Wiley Online Library; 2017;20:21585. doi: 10.7448/IAS.20.1.21585.

26. Low AJ, Mburu G, Welton NJ, May MT, Davies CF, French C, et al. Impact of opioid substitution therapy on antiretroviral therapy outcomes: a systematic review and meta-analysis. Clin Infect Dis. Oxford University Press. 2016;63: 1094-104. https://doi.org/10.1093/cid/ciw416.

27. Karamouzian M, Shokoohi M, Kaplan RL, Noroozi A, Sharifi H, Baral SD, et al. Characterizing the relationship between incarceration and structural risks among female sex workers in Iran: findings of a nationwide biobehavioral surveillance survey. Ann Epidemiol. Elsevier. 2019;35:29-34. https://doi.org/ 10.1016/j.annepidem.2019.04.011.

28. Moradi G, Darvishi S, Asaadi L, Zavareh FA, Gouya M-M, Tashakorian M, et al. Patterns of drug use and related factors among prisoners in Iran: results from the national survey in 2015. J Prim Prev. Springer. 2020;41:1-10. https://doi.org/10.1007/s10935-019-00574-z.

29. Nikpour G. Drugs and drug policy in the Islamic Republic of Iran. Middle East Briefs [Internet]. 2019;119:2-7 Available from: www.academia.edu/ download/56979517/CrownCenterMiddleEastBriefPDF.pdf.

30. Marsden J, Stillwell G, Jones H, Cooper A, Eastwood B, Farrell M, et al. Does exposure to opioid substitution treatment in prison reduce the risk of death after release? A national prospective observational study in England. Addiction. Wiley Online Library. 2017;112:1408-18. https://doi.org/10.1111/ add.13779.

\section{Publisher's Note}

Springer Nature remains neutral with regard to jurisdictional claims in published maps and institutional affiliations.

Ready to submit your research? Choose BMC and benefit from:

- fast, convenient online submission

- thorough peer review by experienced researchers in your field

- rapid publication on acceptance

- support for research data, including large and complex data types

- gold Open Access which fosters wider collaboration and increased citations

- maximum visibility for your research: over $100 \mathrm{M}$ website views per year

At $\mathrm{BMC}$, research is always in progress.

Learn more biomedcentral.com/submissions 